International Journal of Computer- Aided Technologies (IJCAx) Vol.3, No. 2/3, July 2016

\title{
Design And Development Of Custom Change MANAGEMENT WORKFLOW TEMPLATES AND HANDLERS For VEHICLE DESIGN RELEASE.
}

\author{
Vijay B. Tatipamde ${ }^{1}$ and Dr.Vilas M. Nandedkar ${ }^{2}$ \\ ${ }^{1}$ SY M.Tech (Mechanical-PLM) student, Shri Guru Gobind Singhji Institute of \\ Engineering and Technology, Vishnupuri, Nanded, India \\ ${ }^{2}$ Professor, Production Engineering, Shri Guru Gobind Singhji Institute of Engineering \\ and Technology, Vishnupuri, Nanded, India
}

\begin{abstract}
A large no. of automobile companies finding a convinient way to manage design changes with the use of various PLM techniques. Change in any product is something that should occur on timely basis to match up with customer requirement and cost reduction. The change made in the vehicle designs directly affects various concerned agencies. Automobile Vehicle structures contains thousands of parts and if there is any change is occurring in child parts then it becomes important to track that impacted part, propose a solution on that part and release a new assembly structure with feasible changes such that all efforts need to be done for cost reduction.
\end{abstract}

\section{KEYWORDS}

Workflow, Change Management, Custom-handlers, Teamcenter Unified, Assembly Structure, EBOM

\section{INTRODUCTION}

With the use of product life cycle management system, the auditor and customer could electronically deal with the compulsory approvals and inspection of the design and design changes in preparation. 3 distinct phases of change management traversing from need of change to release of changed designs with proposed solution can be efficiently managed in PLM. But data duplication and reuse of data is the next big things that are concerned with cost reduction efforts. Certain error checks and manual handling of data need to countered with newer technologies. 


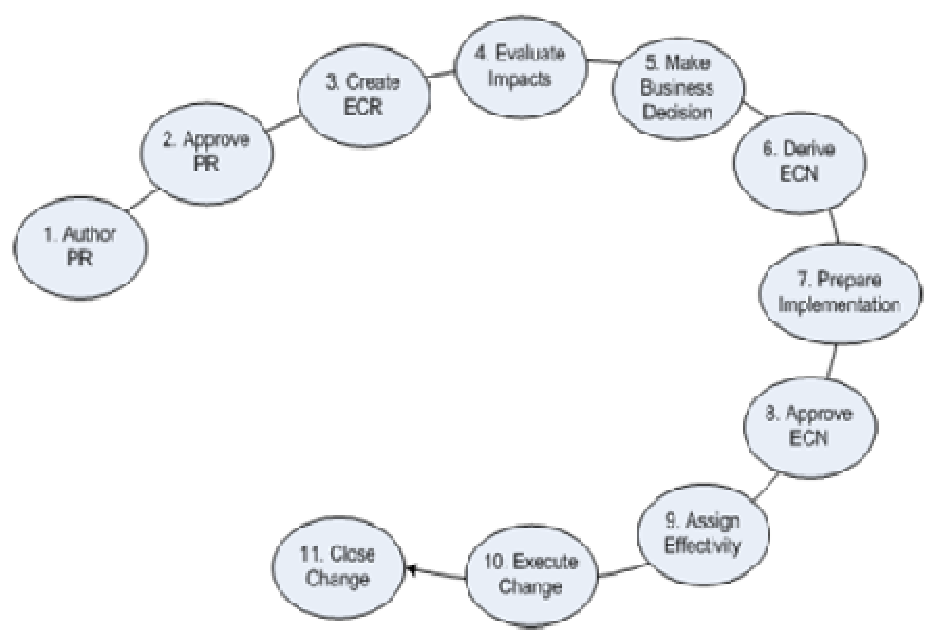

Figure 1. Change Management Cycle [7]

$\mathrm{CM}$ provides an auditable history of the objects used in a process, making an object's various usages traceable. Industries can use CM to propose, incorporate, review, and approve changes. Regardless of when CM comes into play at a company, it is typically an ongoing process which continues until the end of the product's life cycle.

You can classify a change as fast track or standard track. In a fast track process, the change does not go through a formal review process, while a standard track follows a more rigorous process, and may include a schedule to manage the required tasks.

\section{Problem Statement}

Change in vehicle design arises due to various reasons like customer requirement, cost reduction, product development and so on. As the design change need arises it should be mapped in a release process. The current Team center enterprise framework has design release issues which need to be addressed and solved through a new design release workflow in Team center unified by mapping all the business processes.

\section{LITERATURE REVIEW}

The Paper Presented by Eduard-Ionel Ionescua, Alexandrina Meru, Rodica Dragomiroiua, concluded in their paper "Towards a new approach to supporting top managers in SPI organizational change management" that The Effective CM Solution will accelerate speed, eliminate unnecessary cost and Improve innovation and it will provide reliable information to help management make superior decisions[2].

The Paper Presented by Vildan Kocar, Ali Akgunduz , "ADVICE: A virtual environment for Engineering Change Management, concluded in their that how an effective virtual organization devides task responsibilities from top level managers to ground level personals and take reviews from them for final decision. 


\section{METHODOLOGY}

\subsection{Change Management Business objects}

Change objects capture the necessary change information either as part of their properties or through establishing relations with other objects.

- Problem report

- Enterprise change request

- Enterprise change notice

\section{Define problem Analyze impact Implement change}

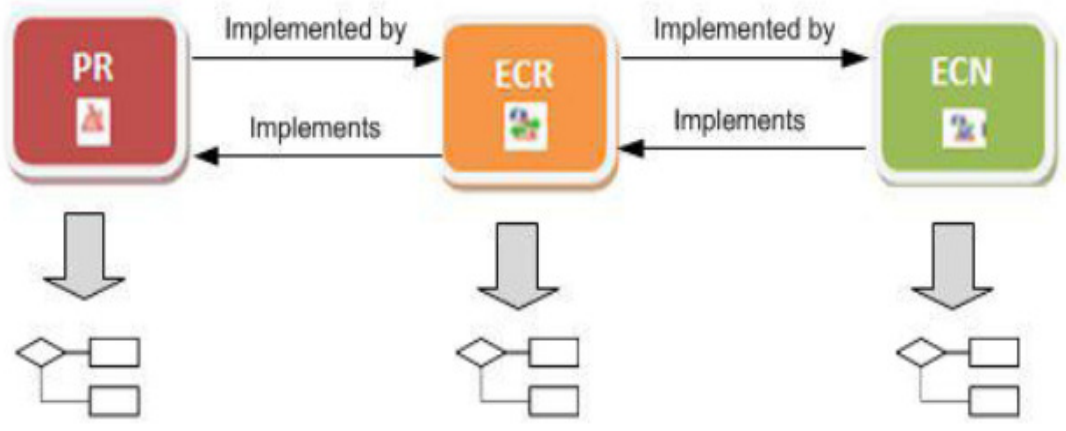

Workflows

Figure 2. Change Objects [7]

\subsection{Assembly structure creation in PLM software}

\begin{tabular}{|c|c|c|c|}
\hline \multirow{2}{*}{\multicolumn{4}{|c|}{ Do0114/A;1-Chassis Assy (View) - Latest Working - Date - "Now" }} \\
\hline & & & \\
\hline \multirow{2}{*}{ 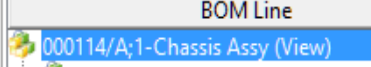 } & Item Type & Rule confi... & Item Rev Status \\
\hline & \multicolumn{2}{|l|}{ Item } & Released \\
\hline $3000115 / A ; 1-X-F r a m e$ & Item & Has Status... & Released \\
\hline 000116/A;1-Suspension & Item & Has Status... & Released \\
\hline $3000117 / A ; 1-L e a f$ Spring & Item & Has Status... & Released \\
\hline 3 000118/A;1-Coil Spring & Item & Has Status... & Released \\
\hline 3 000119/A;1-Spring hanger & Item & Has Status... & Released \\
\hline 000120/A;1-Torsion bar & Item & Has Status... & Released \\
\hline $3000121 / A ; 1-M u f f l e r$ & Item & Has Status... & Released \\
\hline 3 000122/A;1-Hotchstick drive & Item & Has Status... & Released \\
\hline 000123/A;1-Upper control arm & Item & Has Status... & Released \\
\hline 000124/A;1-Shackle & Item & Has Status... & Released \\
\hline 3000125/A;1-Axle housting & Item & Has Status... & Released \\
\hline B 000126/A;1-Tail pipe & Item & Has Status... & Released \\
\hline 3 000127/A;1-Rear stabilizer bar & Item & Has Status... & Released \\
\hline 3000128/A;1-Shock absorber & Item & Has Status... & Released \\
\hline
\end{tabular}

Figure 3. EBOM in PLM 
International Journal of Computer- Aided Technologies (IJCAx) Vol.3, No. 2/3, July 2016

vehicle assembly structures contains no. of parts all these are need to be considered while creation of assemblassembly structures contains no. of parts all these are need to be considered while creation of assembly structure.

\subsection{Use of change management workflows for managing assembly structure}

To release such complex structure 3 distinct change management workflows namely PR (Problem Report), ECR (Engineering Change Request) and ECN (Engineering Change Notice) are need to be implemented.

Problem Report will consist of analyzing possibly of change in product design if such issue occurs then PR will be raised by end user of on field users.

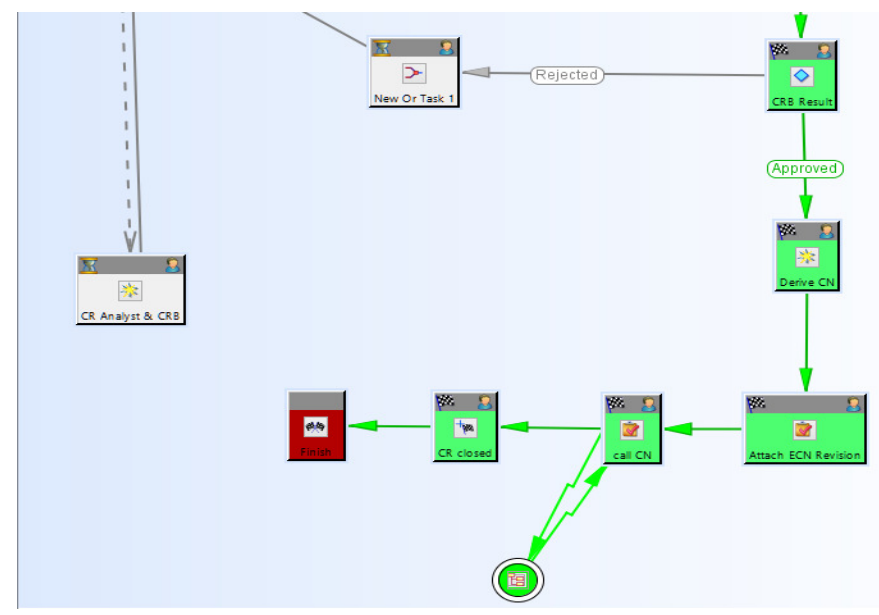

Figure 4. ECR Workflow

ECR Workflow will consist of change specialist assigns the ECR to an analyst. The analyst identifies the items impacted by the change, prepares supporting documentation, and prepares a high-level proposal for the actions required to implement the change.

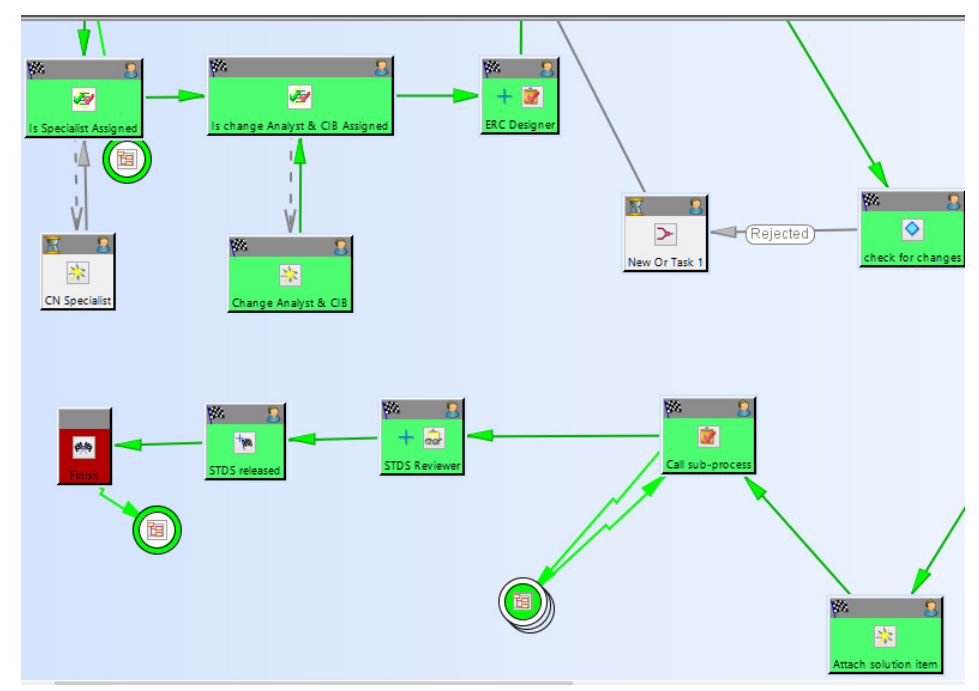

Figure 5. ECN Workflow 
International Journal of Computer- Aided Technologies (IJCAx) Vol.3, No. 2/3, July 2016

Finally ECN Workflow consists of approval review from change implementation board on feasibility of design change.

\subsection{Teamcenter Customization}

\subsubsection{ITK}

The Integration Toolkit (ITK) is a set of server-side software tools you can use to integrate thirdparty or user-developed applications with Teamcenter. The ITK is a set of $\mathrm{C}$ and $\mathrm{C}++$ functions used directly by Teamcenter and UG. The Integration Toolkit is a set of software tools that act as a programmatic interface to Teamcenter. It is the means by which both internal and external applications integrate with the Teamcenter. Internal applications are those supplied such as UG. External applications are those that you decide to integrate into Teamcenter [7]

\subsection{Use of ITK Handler for tracking part level make buy indicator status}

\subsubsection{Programmatic Authentication}

The entire programme code is formed from standard c and c++ functions and ITK API's.Firstly part is found out in the system on which make buy status value need to be updated. SA unique property has been set on part which is matched with target attachment. And finally if value is not found then it asks for user to update value on part such that dummy part information will not propagated in the system.

\section{Code Fragment 1-Find attachments}

This function will find all the attachments to be find out

Status=EPM_ask_attachments (rootTask_t, EPM_target_attachment, \&count, \&pTagAttch);

\section{Code Fragment 2-Find property on part}

This function ask for required attribute from part

ITKCALL (AOM_ask_value_string (pTagAttch[i],"property name", value of property));

\section{Code Fragment 3- Shows Error message}

This function will displays error message

Status=EMH_store_error_s2 (EMH_severity_information,ITK_errStore,itemid, "error message" ) ); 
International Journal of Computer- Aided Technologies (IJCAx) Vol.3, No. 2/3, July 2016

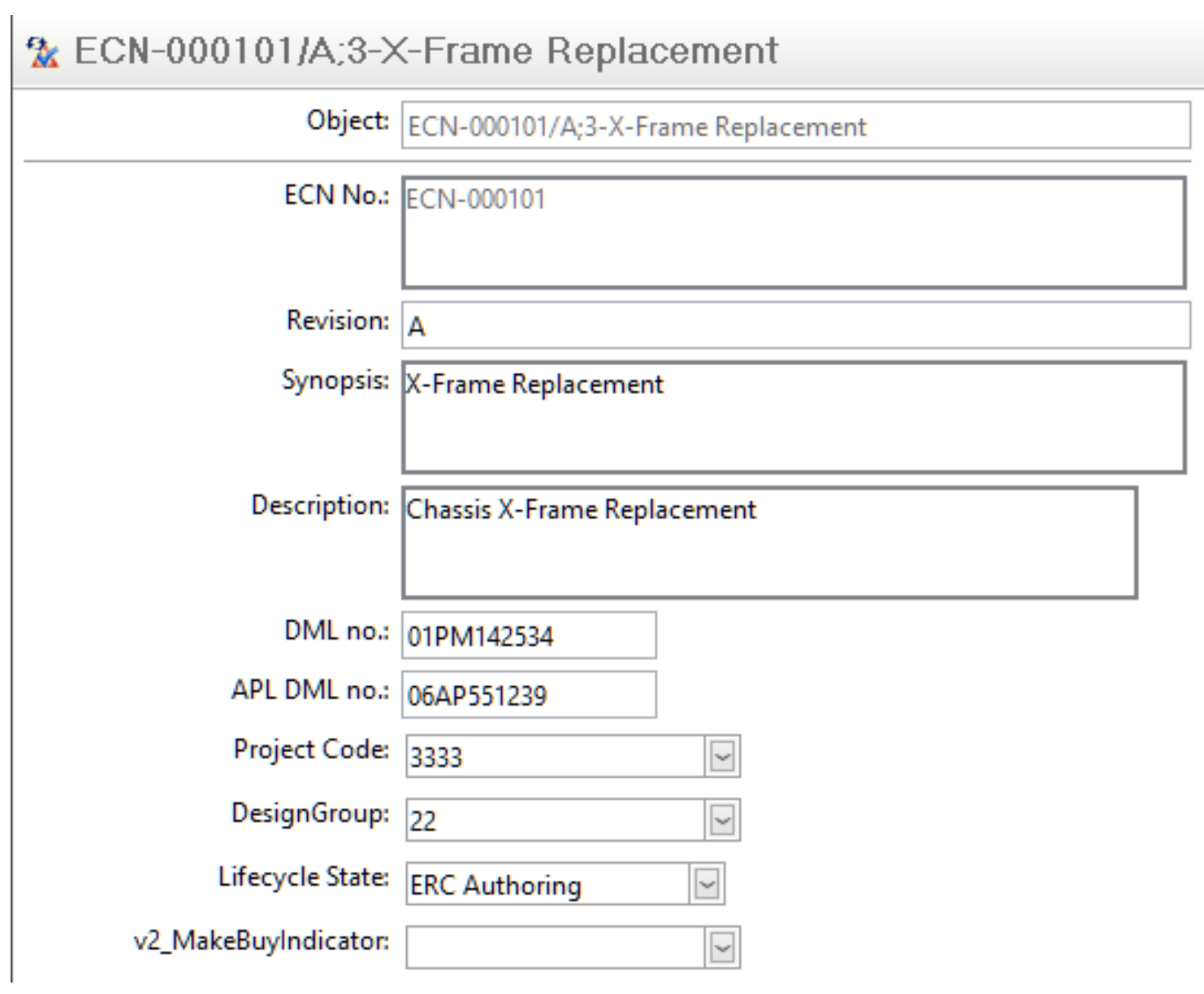

Figure 6. ECN object

The child part component which will be used in vehicle assembly will have make buy indicator level on it. Users are enforced to specify one value from available list of values.

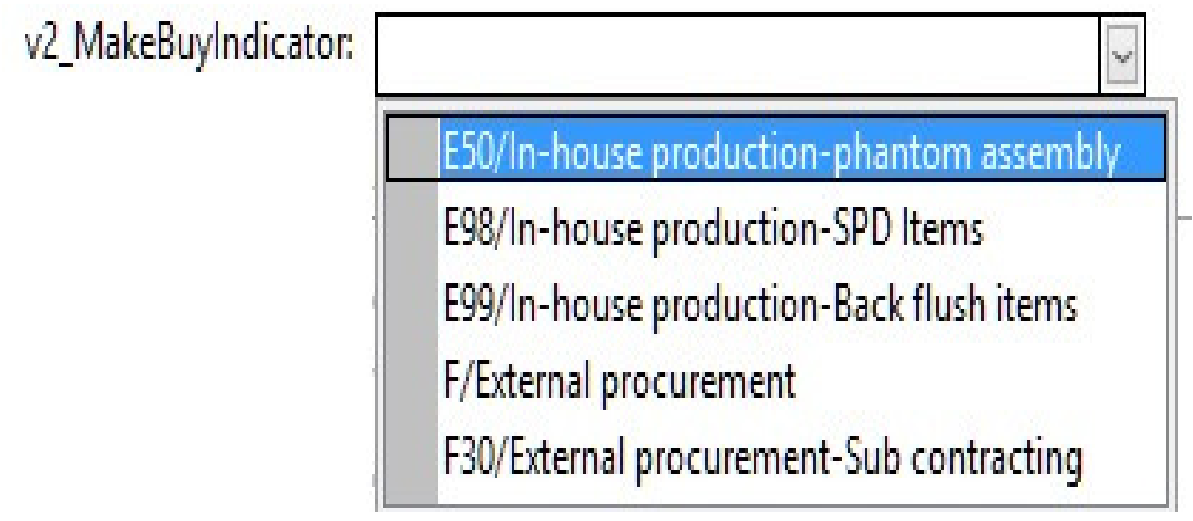

Figure 7. Make Buy List of Values

Vendor information get updated on each part which ensures part availability in system and this data useful in SAP for creating purchase orders (PO). 


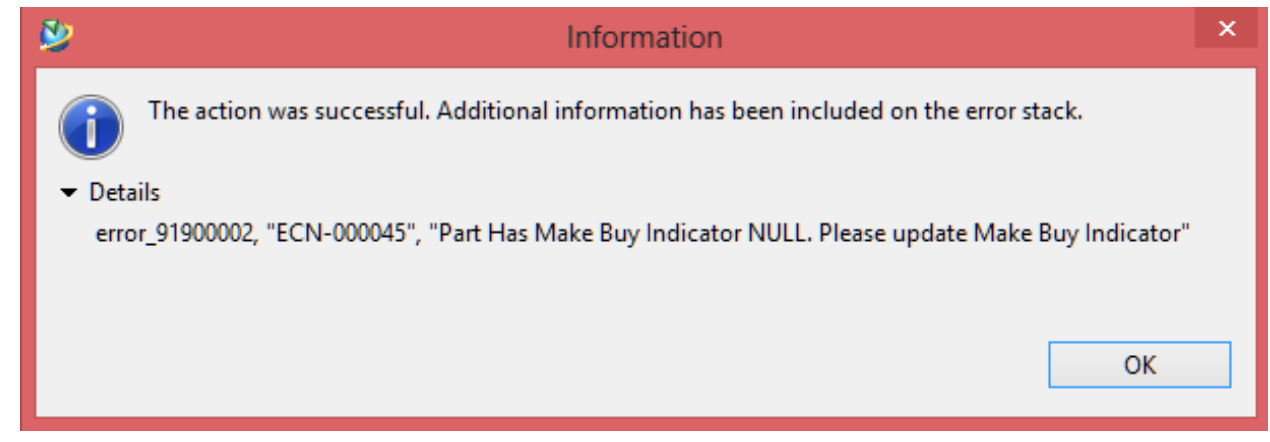

Figure 8. Make Buy status error message

The provision in this paper is made which will ask user about make buy indicator on part that is such value cannot be set blank if it is set blank by user an error will come to update make buy indicator level.

\section{Conclusions}

Change management workflow spans each individual pesonel in an industry, take reviews and feedback from concerned authorised persons and unauthorised persons are delegated from task signoff responsibilities.

Vehicle design is got approval from various agencies by releasing Vehicle Assembly structure through change management workflows Error checks has been set which confirms dummy parts will not get approved from end users End-to-end departmental mapping has been done which minimizes manual work . The virtual organization is designed for the participants in the CM process.Each part will be identified by a unique part number which identifies duplicate part numbers in database.Vendor information get updated on each part which ensures part availability in system and this data useful in SAP for creating purchase orders (PO).

\section{REFERENCES}

[1] Joze Tavcar, Joze Duhovnik, (2005)"Engineering change management in individualand mass production", Robotics and Computer-Integrated Manufacturing 21 205-215

[2] Eduard-Ionel Ionescua, Alexandrina Meru, Rodica Dragomiroiua (2013), "Towards a new approach to supporting top managers in SPI organizational change management" - International Conference on Health and Social Care Information Systems and Technologies.

[3] Aynar and Ducellier(2008) "From workflow specification to implementation", International Design Conference Dubrovnik - Croatia, May 19 - 22, 2008.

[4] Anna Wasmer, Gunter Staub, Regine W. Vroom, "An industry approach to shared, crossorganizational engineering change handling - The road towards standards for product data processing”, Computer-Aided Design, Vol. 43-5 (2011), 533-545

[5] Eduard-Ionel Ionescua, Alexandrina Meru, Rodica Dragomiroiua, "Role of Managers in Management of Change", Procedia Economics and Finance, Sibiu-Romania, Vol. 16 (2014)

[6] Rob Dekkers, C. M. Chang, Jochen Kreutzfeldt, "The interface between product design and engineering and manufacturing: A review of the literature and empirical evidence", International Journal of Production Economics, Vol. 144-1 (2013), 316-333

[7] Teamcenter Online Help (2008)

[8] Vildan Kocar, Ali Akgunduz , "ADVICE: A virtual environment for Engineering Change Management”, Computers in Industry, Vol. 61-1 (2010), 15-28

[9] Kamel Rouibah, Kevin R. Caskey, Change management in concurrent engineering from a parameter perspective", Computers in Industry, Vol. 50-1 (2003), 15-34 
International Journal of Computer- Aided Technologies (IJCAx) Vol.3, No. 2/3, July 2016

\section{Authors}

Vijay B. Tatipamde

B.Tech (Production Engineering)

Persuing M.Tech in Mechanical-PLM

SGGSIE\&T, Nanded

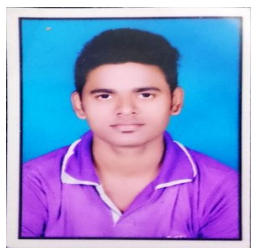

